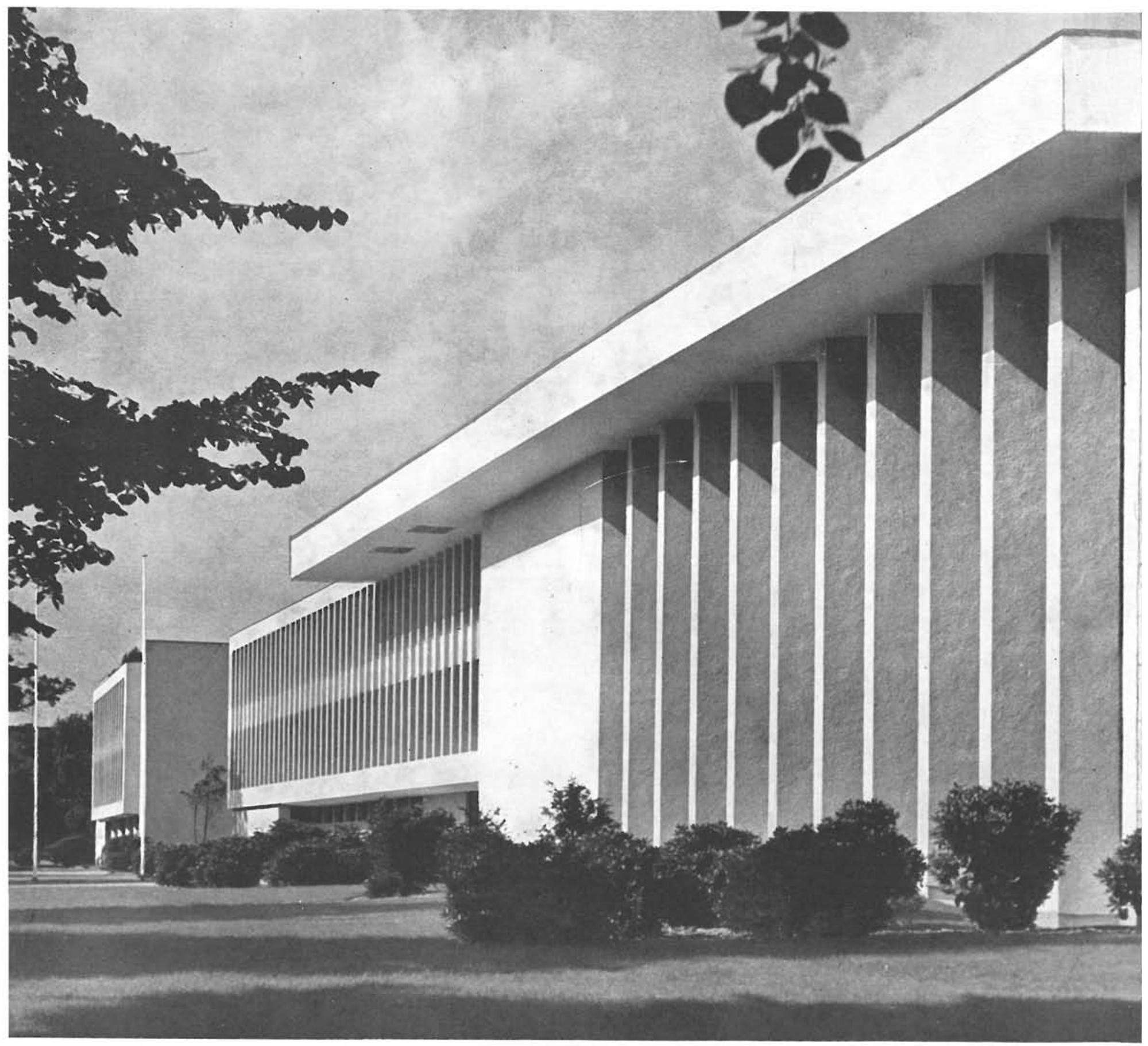

$142-14$

\title{
universidad libre de Berlín
}

F. H. SOBOTKA y G. MULLER, arquitectos 


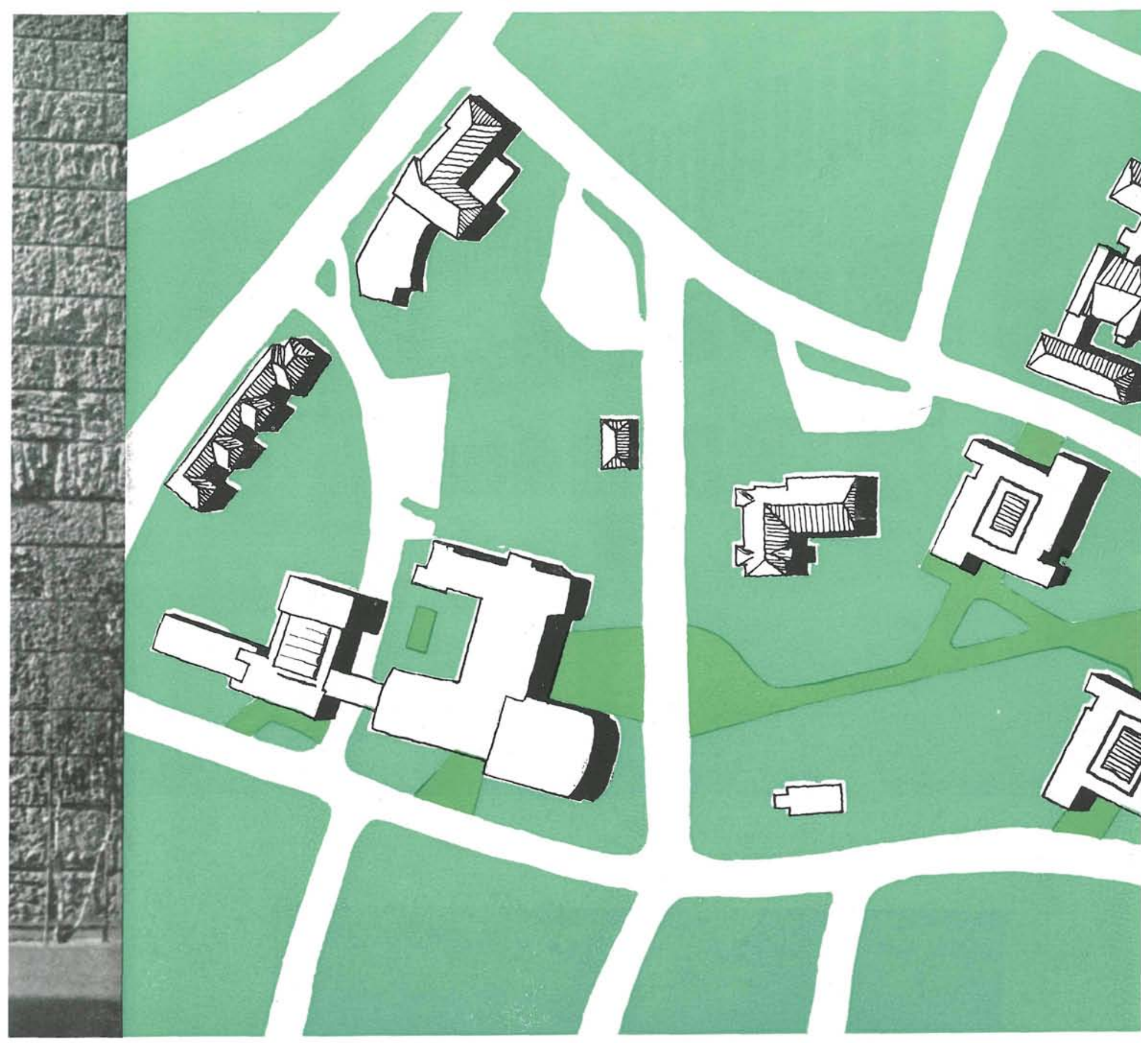

Berlín fué dividido al terminar la segunda guerra mundial en dos zonas: Occidental y Oriental. Su, desde antiguo, famosa Universidad quedó situada casi en su totalídad en zona soviética. Se produjeron serias dificultades para el acceso a ella de los estudiantes del Berlín libre y, por este motivo, las autoridades del mismo, para dar solución rápida y definitiva a este problema, convocaron un concurso: "La Universidad libre de Berlín».

Se escogío como emplazamiento Dahlem, zona residencial pintoresca, donde ya existían centros universitarios de importancia secundaria.

Los arquitectos F. H. Sobotka y G. Müller obtuvieron el primer premio, en reñida competencia con otros veintiséis participantes, $y$ les fué adjudicada la construcción del edificio.

La "Henry Ford Fundation»» financió e hizo posible su construcción; el coste aproximado de la misma fué de siete millones de marcos.

Al proyectar la Universidad los arquitectos rehuyeron deliberadamente de construcciones masivas, buscando formas abiertas para que la naturaleza exterior forme parte de los ambientes internos.

situación 

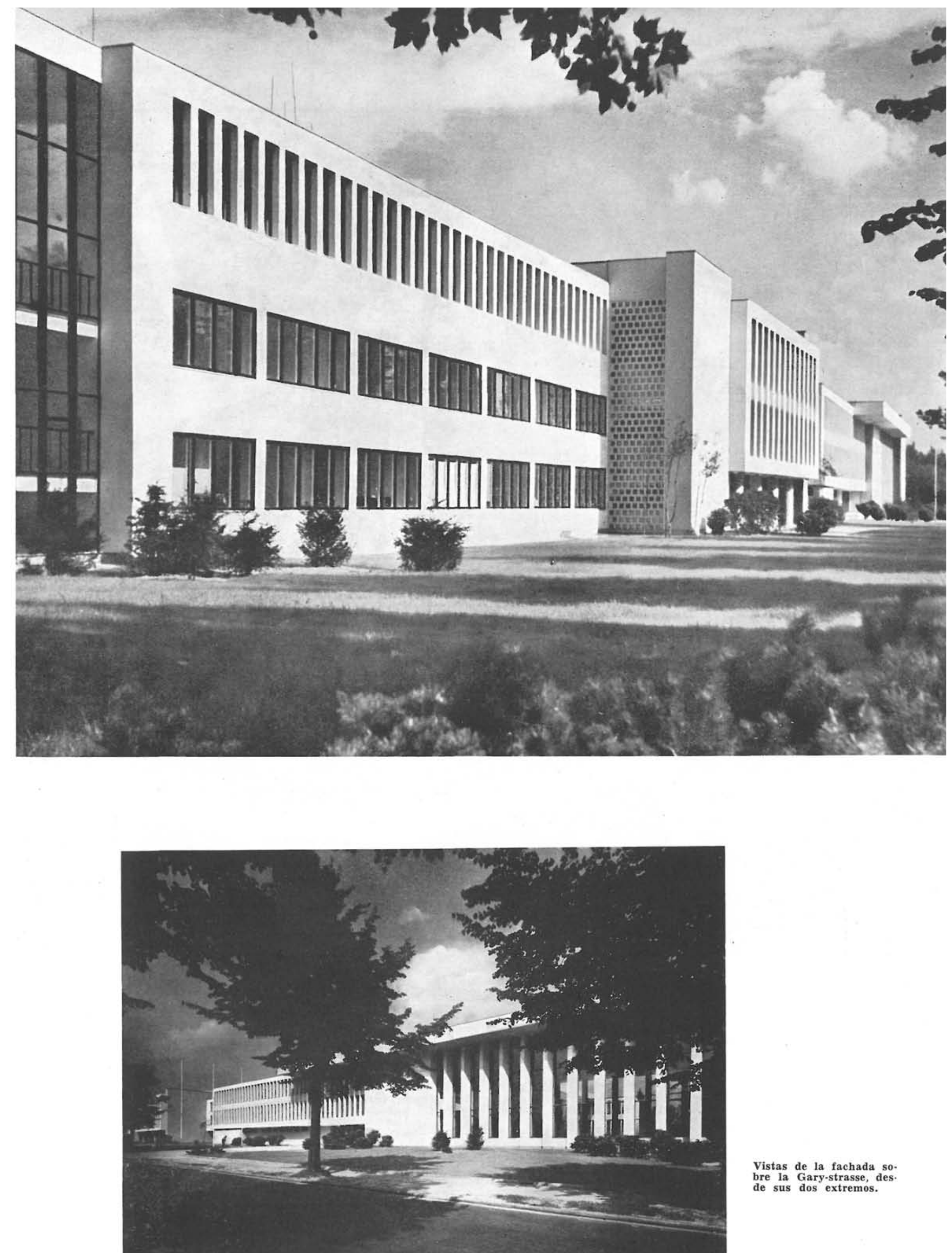

Vistas de la fachada so.

bre la Gary-strasse, des.

de sus dos extremos. 


\section{pla $n$ ta baja}

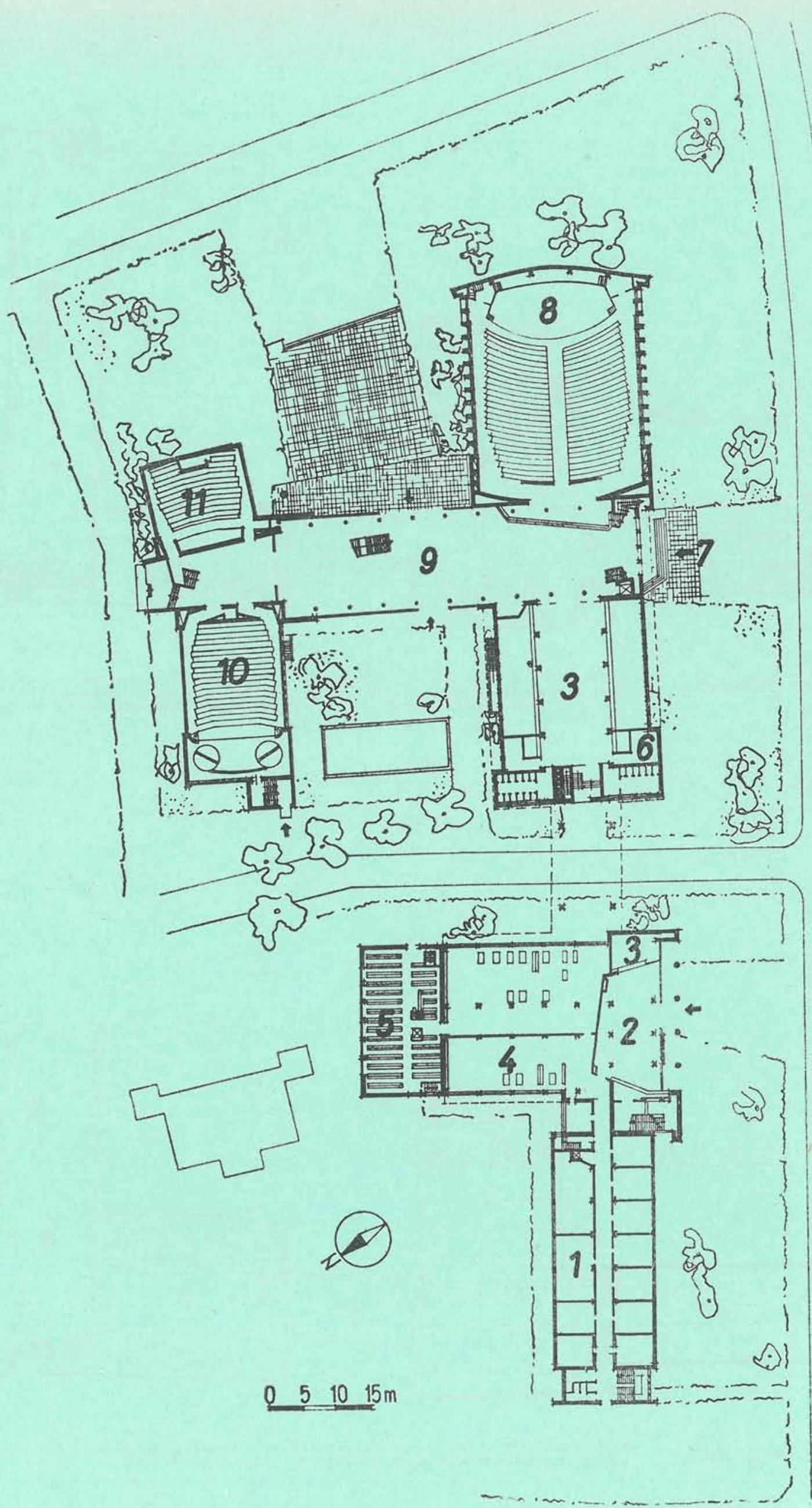

1. Administración.

2. Hall de ingreso.

3. Guardarropa.

4. Entrada.

5. Almacén de libros.

6. Personal.

7. Entrada principal.

9. Hall-Sala de exposiciones.

10. Gran Auditorio.

11. Auditorio. 


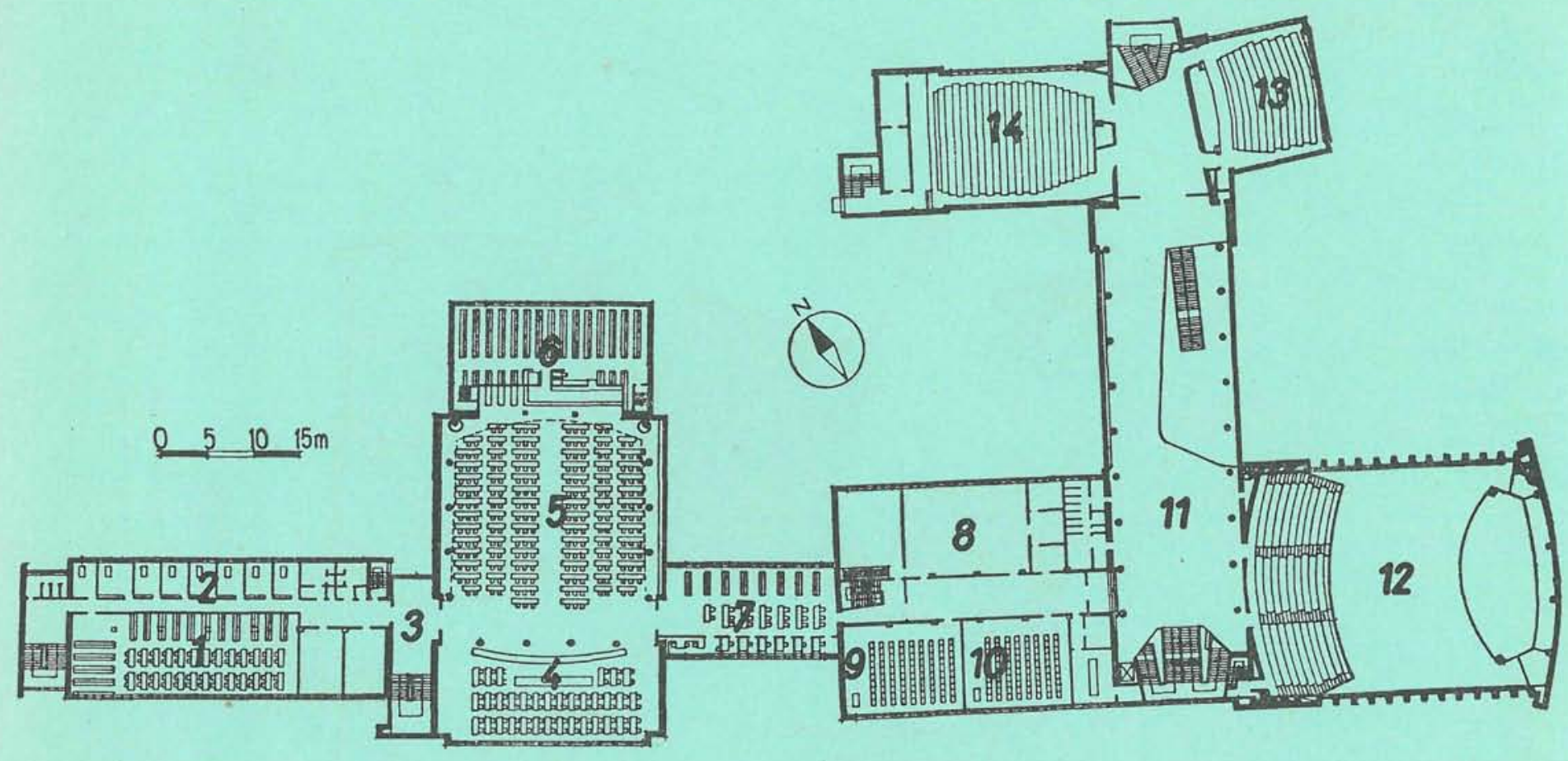
$\begin{array}{ll}\text { planta primera } & \text { 1. Seminario,-2. Despachos de profesores. }-3 \text {. Control. }-4 \text {. Sala de revistas. }-5 \text {. Sala de lec- } \\ \text { tura. -6. Almacén de libros. }-7 \text {. Archivos. }-8 \text {. Collegium musicum. }-9 \text {. Seminarios. }-10 \text {. Semi- }\end{array}$ narios.-11. Hall y galería superior.-12. Paraninfo.-13. Sala de conferencias. -14 . Sala de conferencias.

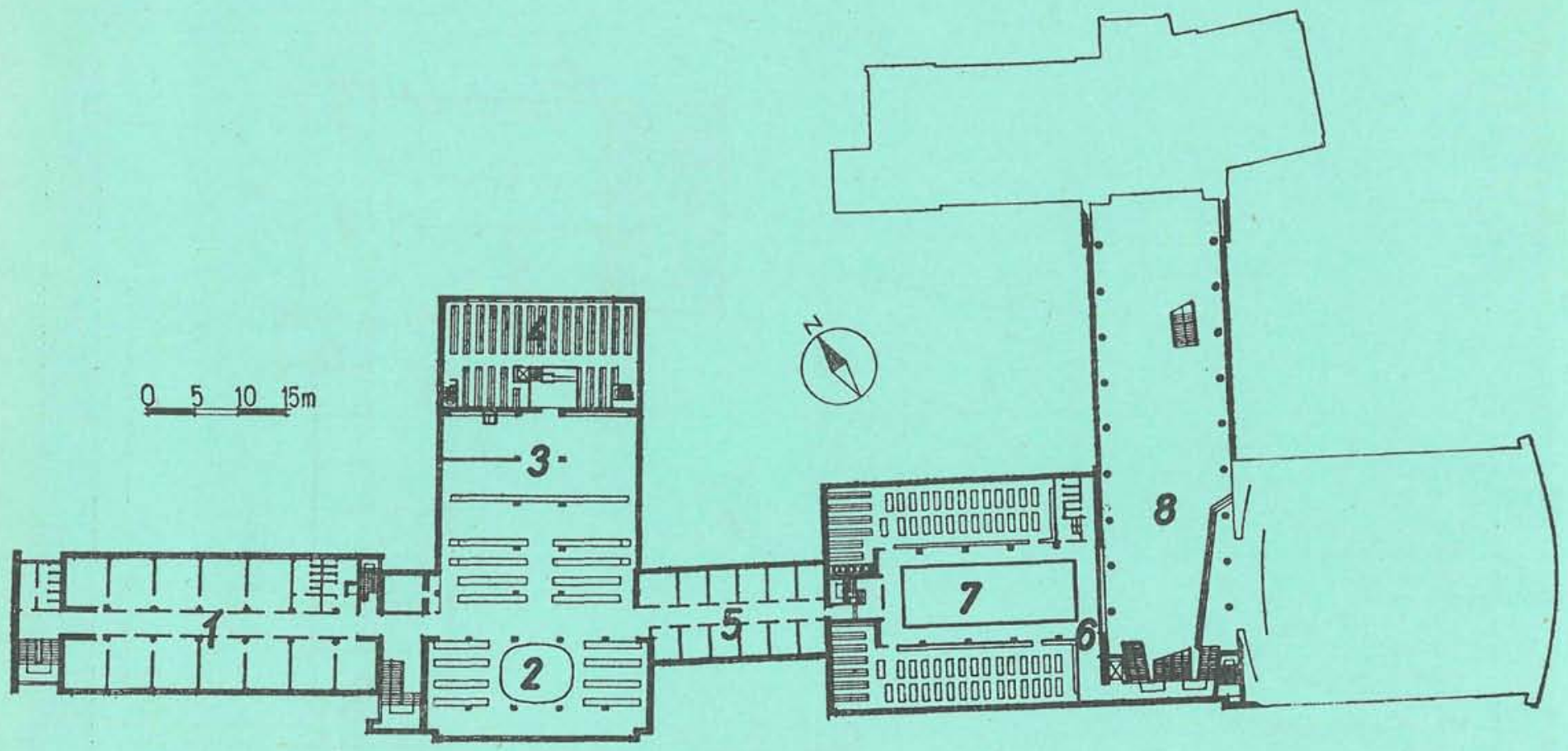

$\begin{array}{ll}\text { planta segunda } & \text { 1. Administración. }-2 \text {. Sala de catálogos. }-3 \text {. Sección circulante. }- \text { 4. Almacén de libros. }-5 \text {. Des- } \\ \text { pachos de profesores. }-6 \text {. Galeria. }-7 \text {. Vacio del guardarropa. }-8 \text {. Hall. }\end{array}$ 


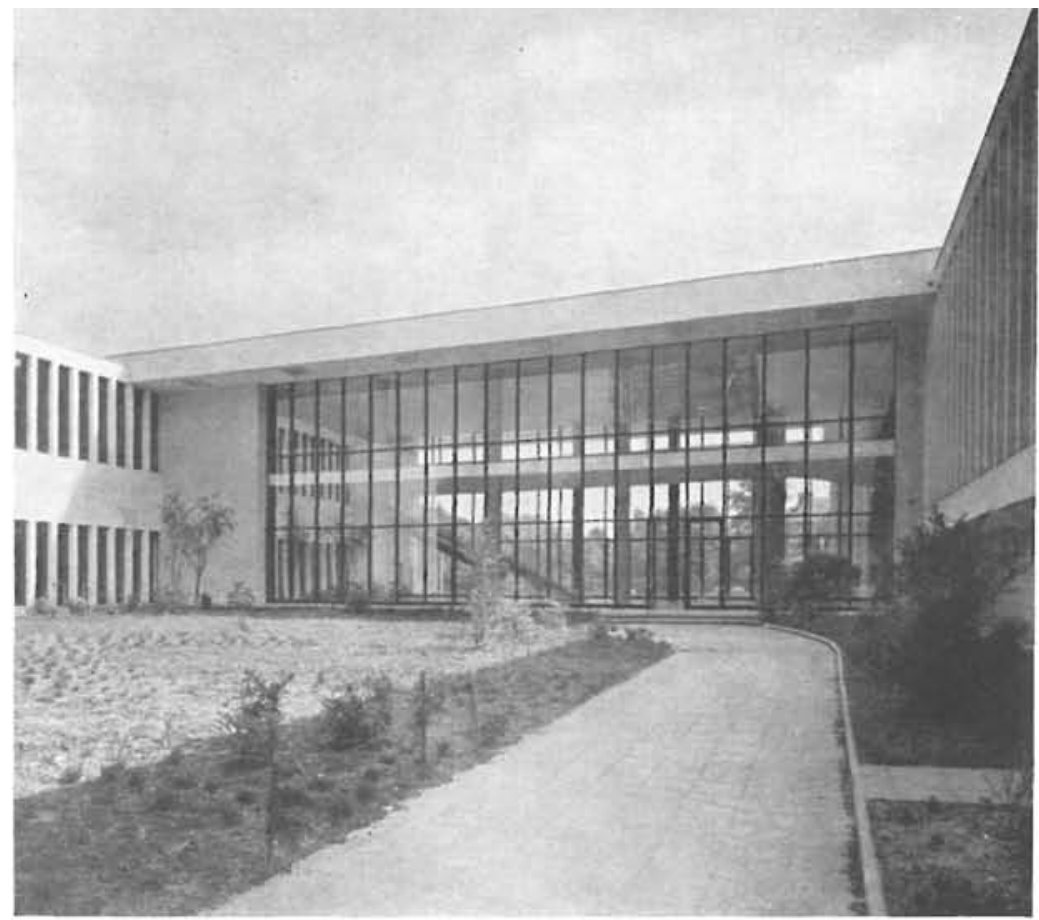

En sus fachadas se da de lado a composiciones imponentes. Se buscan soluciones sencilles, nacidas de la planta, y volumenes in terios. en todo el proyecto está presente la ción natural excelente. excelente.

En planta rigen la composición dos ejes que se cortan ortogonalmente: la cruz, de brazos desiguales, orienta su brazo mayor en direccion SE.-NO. Sobre el mayor se situaron: a menor: l pasos perdidos, galería de exposiciones y dos amplios auditorios. I a zona administrativa incluye, además de los locales que le son propios, despachos privados para los profesores, pios, despachos privados para los profesores, conta de una sala de archivos una de revistas, la gran sola de lectura, despachos individuales para investigaciones, y guardarropas. El almacén de libros, capaz para un milión de volúmenes, se ha resuelto on un torre de once plantas, provista de ascensor y montacargas, La iluminación cenital de todos los locales de lectura presta a los mis mos condiciones óptimas de intensidad luminosa en las mesas de lectura $y$ planos de trabajo.

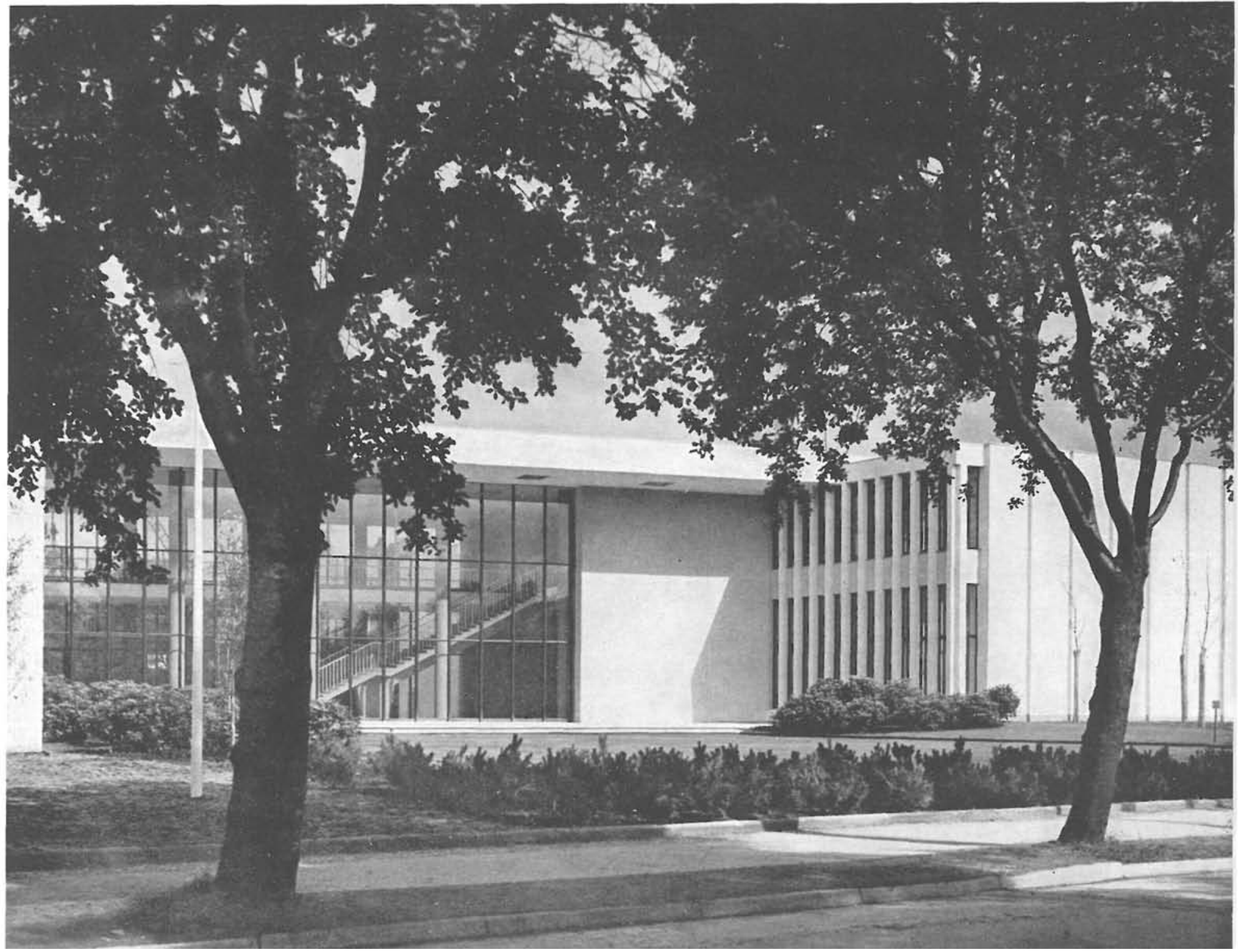



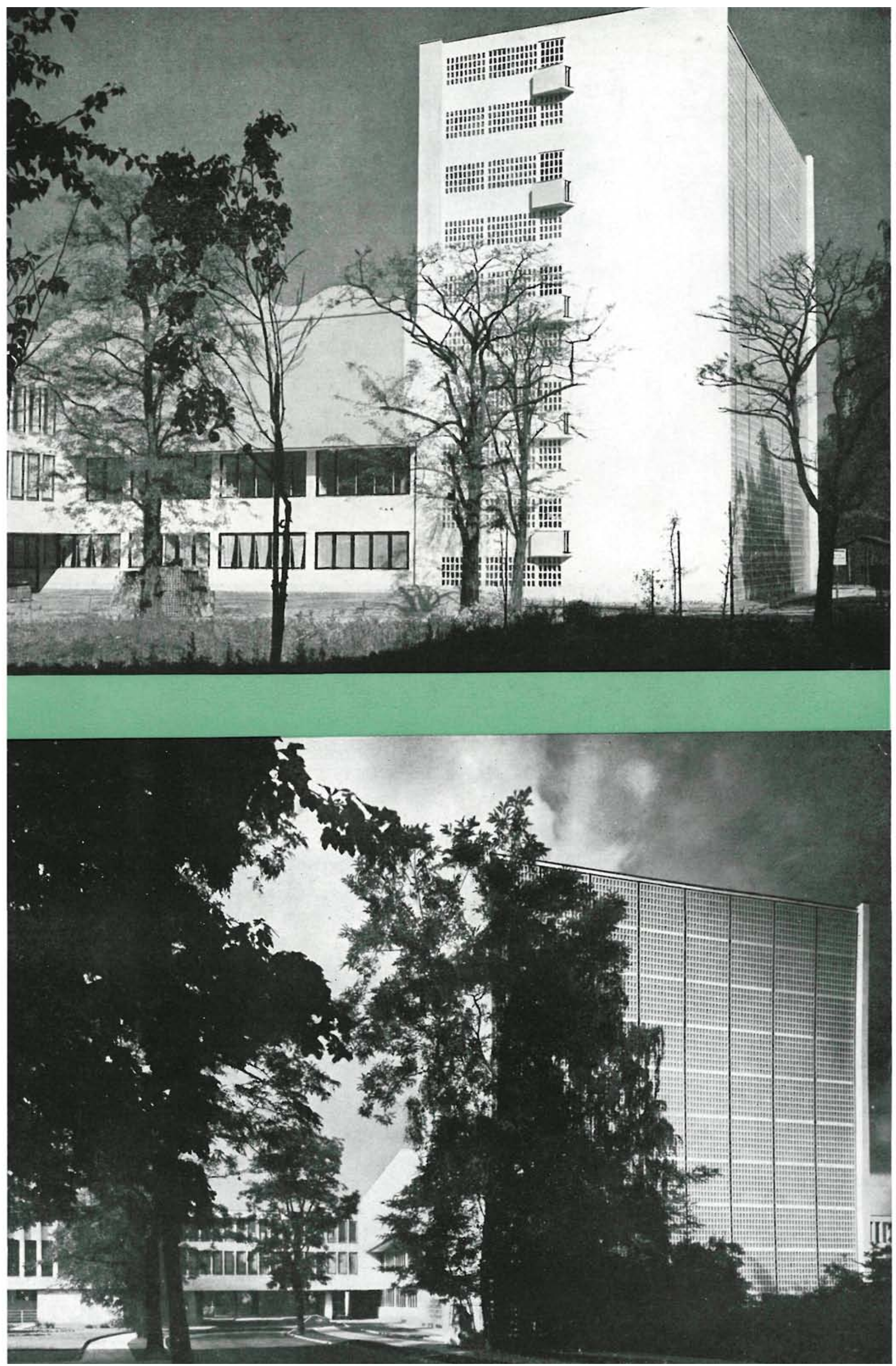
El hall de entrada enlaza, amplia y directamente, con el salón de exposiciones y el gran paraninfo, y por medio de una escalera de trazado libre, con la galería superior. El hall, salón de exposiciones y la galería están iluminados a traves de amplios ventanales. Llenos de luz, con vistas sobre el patio interior ajardinado, el estanque y el parque-frente a la calle Boltzmann-, hacen que sus ambientes sean continuación de la naturaleza que los rodea.

El paraninfo, de $25 \times 30 \mathrm{~m}$, de traza sencilla y líneas sobrias, con el anfiteatro realizado sin apoyos en la sala, techos lisos, paredes planas y su frente, sobre la tribuna presidencial, recubierto de madera, es de una sobria elegancia. Por su forma reune excelentes condiciones acústicas. La temperatura ambiente se regula, al igual que en los o un sistema autometico para tos, teatro, etc.
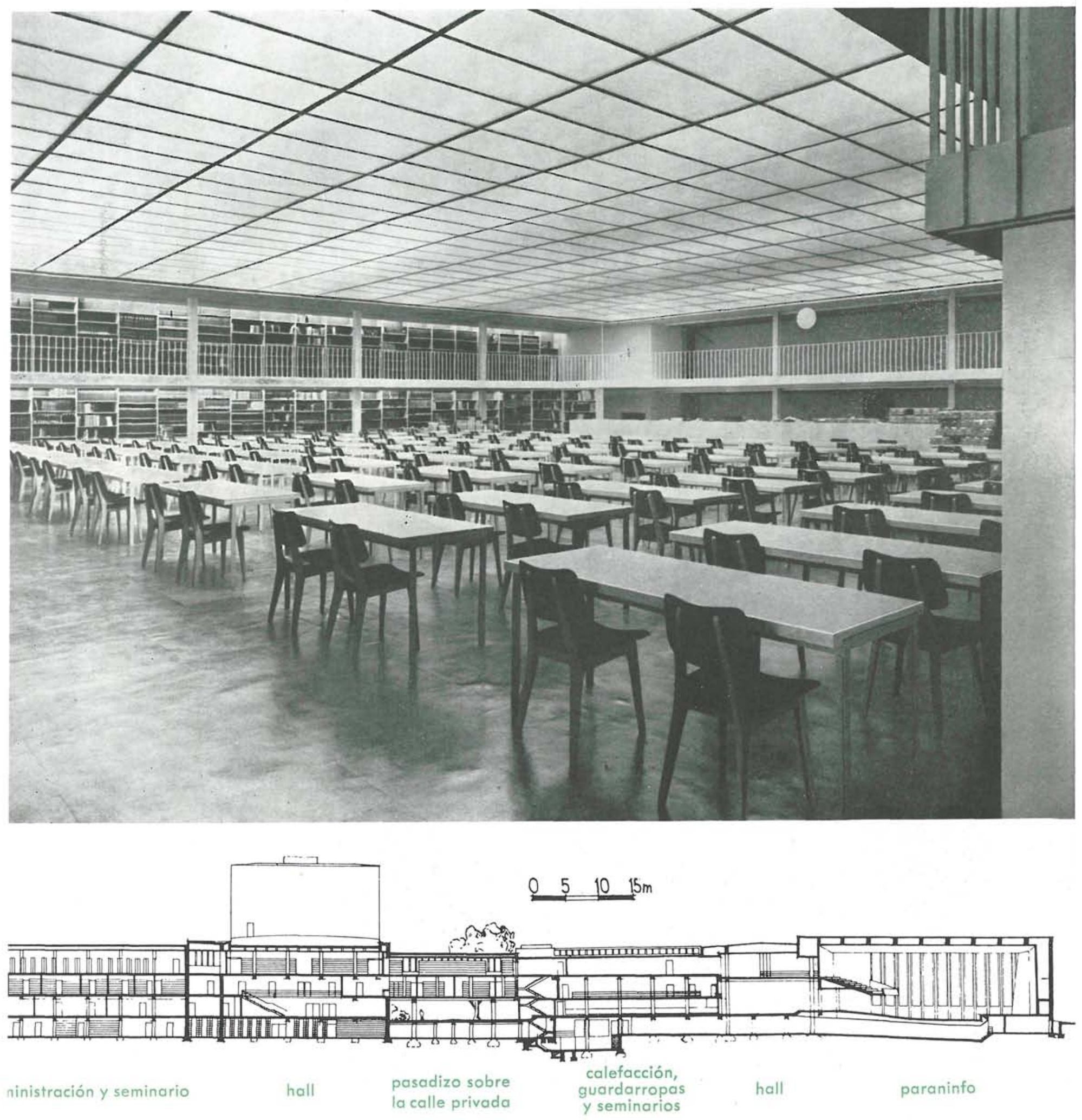


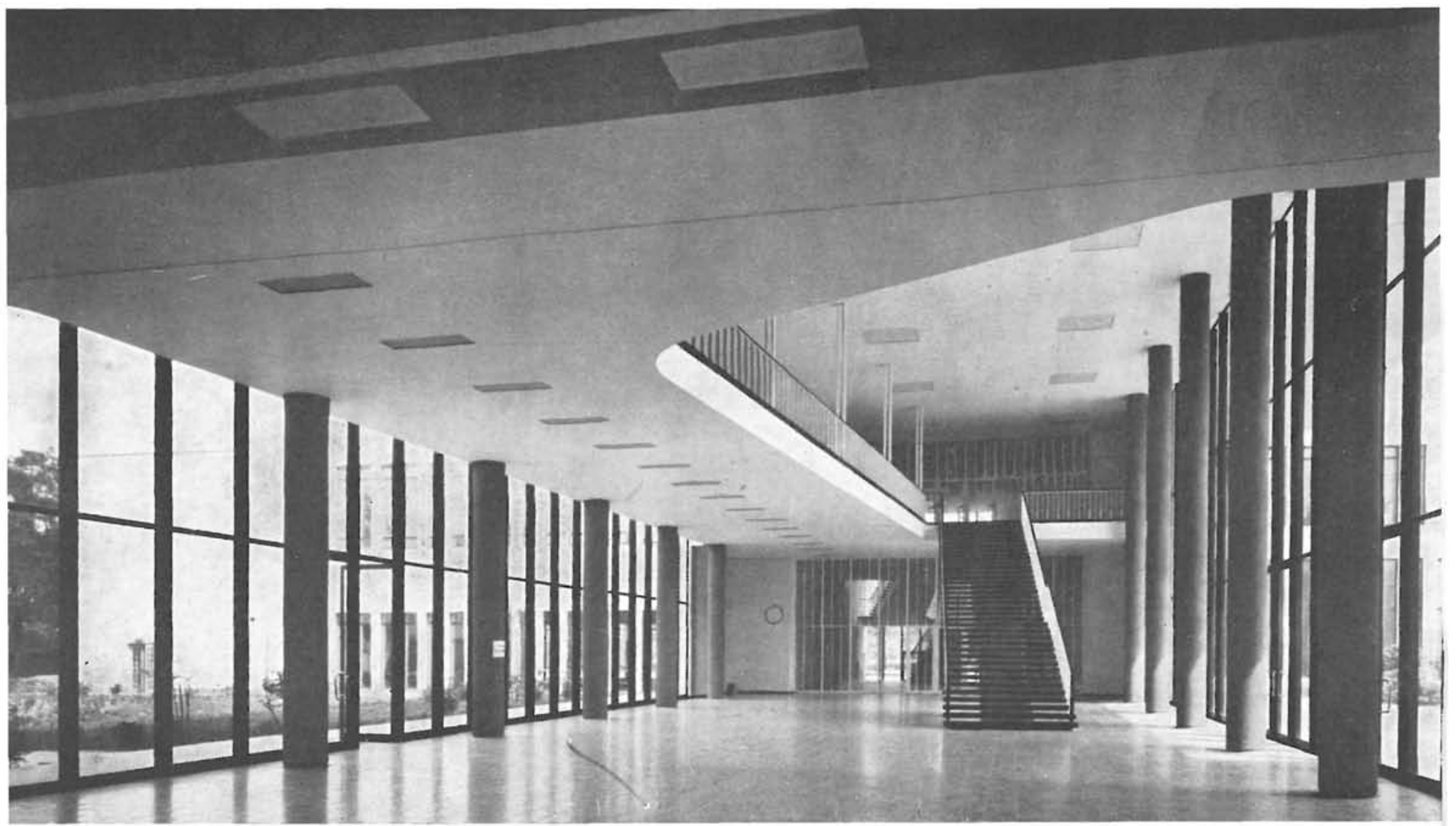

FolOS: FISCHER, HERBERT Y KRAKEWSKY

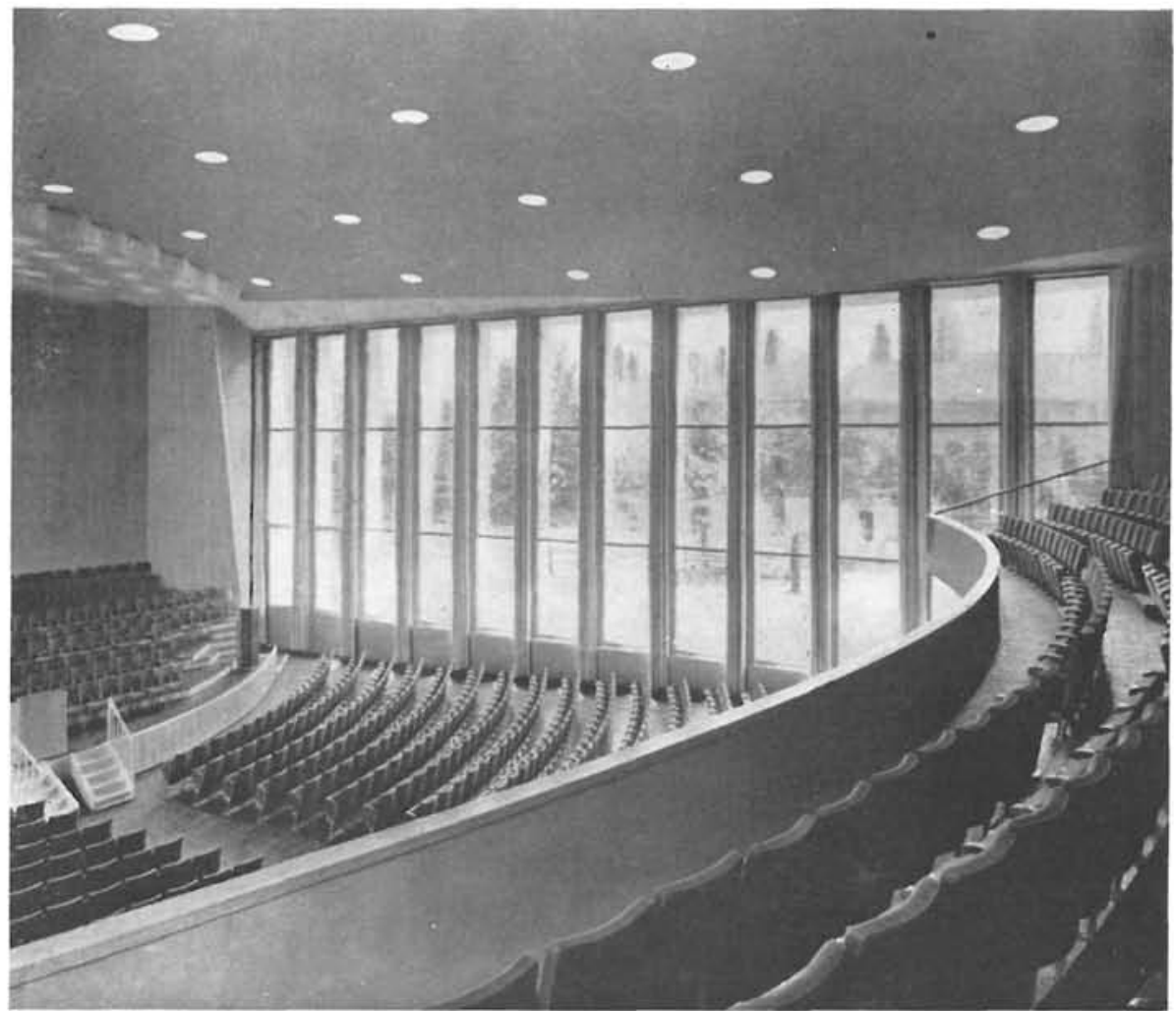

A tenor del gran paraninfo se han construído $\mathrm{y}$ proyectado todos los demás locales y servicios del centro universitario.

Las fachadas-cuyas directrices se apuntaron $\mathrm{ya}$-ofrecen peculiaridades de intes mann, grandes paños de fabrica y Gary de traze dary draza horizontal equilibrada por las líneas verticales de las celosias. La torre almacen es un paráés de un muro celosía de armoniosa composición. En todas ellas es patente el claro
criterio de los arquitectos que las criterio de los arquitectos que las comp partes de un todo que define, total parcine ambientes tanto interiores como exteriores.

La división en zonas de Berlín creó una necesidad. Su resolución tura, realizada con de técnicas más modernas, materiales nobles, fundamentalmente human nobles, dora de ambientes adecuados a las actividades que en ellos se desarrollan y respetuosa con los marcos naturales que la rodean.

F. M. 